\title{
MODEL RANCANGAN DESAIN REVITALISASI KAWASAN NIAGA (Studi Kasus : Pasar Petisah Medan)
}

\author{
Dwi Lindarto ${ }^{1}$, Devin Defriza Harisdani ${ }^{2}$ \\ ${ }^{1,2}$ Departemen Arsitektur, Fakultas Teknik, Universitas Sumatera Utara,20122 \\ ${ }^{\star}$ E-mail : dwilindarto@gmail.com
}

\begin{abstract}
ABSTRAK. Ketimpangan pembangunan kawasan komersial pusat kota menunjukkan perwajahan urban economics berindikasi urban sprawl. Kawasan Niaga Pasar Petisah di Kecamatan Medan Petisah dimanfaatkan sebagai mix-use land use, minimalisasi ruang publik dan in-efisiensi pemanfaatan ruang luar menjadikan degradasi fungsi kawasan publik kota. Ketimpangan pemanfaatan ruang publik tersebut memerlukan upaya revitalisasi kawasan. Berdasarkan analisis awal konsep revitalisasi urban linkage berbasis kearifan lokal, maka dilakukan perencanaan model desain revitalisasi Kawasan Petisah dengan pendekatan retrofitting urban antara linkage visual, struktural, unsur tata guna lahan, arsitektur lokal, sirkulasi, ruang terbuka publik, aktifitas khas lokal. Keluaran penelitian berupa model rancangan desain revitalisasi kawasan niaga dalam wujud gambaran pra-rencana arsitektural zonasi, sirkulasi, pedestrian, ruang publik, parkir dan model tempat berdagang portabel. Model ini merupakan acuan / guide lines bagi revitalisasi kawasan niaga untuk peningkatan dan pemerataan pembangunan ekonomi di pusat kota Medan
\end{abstract}

Kata-kunci : Model Rancangan Desain, Revitalisasi, Kearifan Lokal, Pasar Petisah Medan.

ABSTRACT. Inequality in the development of downtown commercial areas shows that urban economics indicates to become urban sprawl. The commercial area of Pasar Petisah in Medan Petisah District is used as mix-use land use, the minimization of public space and the inefficiency of the use of outer space, making the function of the open area of the city degraded. This imbalance in the use of public space requires efforts in the revitalization of the area. Based on the preliminary analysis of the revitalization concept of urban linkage based on local wisdom, then it will be appropriate to plan the design model for revitalization of the Petisah Area. This design was carried out using an urban retrofitting approach between visual linkage, structural linkage, land use elements, local architecture, circulation, public open space, as well as local special activities. The research output is a design model for the revitalization of the commercial area in the preliminary design of architectural zoning, circulation, pedestrian ways, public space, parking, and portable trading place design. This model is become a guideline for the revitalization of the commercial area to increase and equalize economic development in downtown Medan.

Keywords: Design Model, Revitalization, Local Wisdom, Pasar Petisah Medan

\section{PENDAHULUAN}

Fasilitas perdagangan atau pasar wilayah merupakan salah satu fokus pembangunan infrastruktur suatu kota. Pasar selain sebagai pusat pertumbuhan wilayah merupakan suatu sentral ruang publik yang kemudian berkembang menjadi district growth centre [1]. Dalam kenyataanya tidak semua pusat pertumbuhan wilayah mampu menjadi bangkitan urban economics. Tidak jarang terjadi paradoks pertumbuhan wilayah berupa penurunan efektifitas kinerja wilayah dalam fungsinya sebagai utilitas pendukung kegiatan masyarakat kota [2]. Suasana penurunan efektifitas daya layan atau degradasi vitalitas wilayah juga terjadi di Pasar Petisah Medan dimana kondisi pasar menunjukkan suasana sprawl dalam pemanfaatan fungsi ruang luar. Ketika malam hari kegiatan Pasar Petisah menjadi senyap ditinggalkan oleh penghuni (residential flight) dan kehampaan aktifitas (activity flight). Wilayah ini berada pada posisi strategis di tengah kota dan dilingkupi oleh pusat kegiatan niaga lainnya yang cukup ramai namun kegiatan Pasar Petisah ini hanya bertahan sampai menjelang petang.

Sebagai suatu lingkungan sosial pada kawasan terdapat unsur kegiatan unik yang berpotensi bagi program revitalisasi kawasan. Salah satu inovasi model peningkatan vitalitas kawasan dalam tindak revitalisasi adalah retrofitting suburban [3]. Retrofitting adalah pendekatan revitalisasi yang berbasis sustainable development. Model ini 
memanfaatkan potensi lingkungan (sejarah, makna, keunikan lokasi dan citra tempat) dengan penekanan penggalian potensi kearifan lokal (genius locus) [4]. Penelitian ini merupakan lanjutan dari analisis awal konsep revitalisasi urban linkage berbasis kearifan lokal[5], yang akan menjadi panduan penyusunan model perencanaan revitalisasi pasar Petisah. Model rancangan desain ini merupakan acuan / guide lines bagi revitalisasi kawasan niaga untuk peningkatan dan pemerataan pembangunan ekonomi di pusat kota Medan.

\section{METODE PENELITIAN}

Penelitian ini merupakan kajian dengan pendekatan mixed method [6], yaitu metode sequensial kuantitatif dan metode kualitatif. Secara sequensial kuantitatif merumuskan potensi daya tarik tempat sebagai unsur desain yang berkaitan dengan potensi sense of place, linkage visual, karakter fisik kegiatan. Secara kualitatif dilakukan rancangan model desain revitalisasi dengan batasan potensi sense of place tersebut diatas.

\section{CITRA KOTA}

Sebagai sebuah imaji, sense of place atau citra kota di pengaruhi potensi obyek menarik, hubungan antar obyek dan pengalaman makna ruang [7]. Hasil penelitian terdahulu, menghasilkan identifikasi potensi Landmark, Path, District, Node, Linkage Visual dan arahan Zonasi kawasan Petisah yang digunakan sebagai konsep revitalisasi urban linkage berbasis kearifan lokal [5]. Karakter sense of place dengan potensi Landmark atau tetenger di kawasan ini yaitu mall Carefour, kantor polisi, ruko kado dan bangunan pasar Petisah sebagai titik orientasi penanda kawasan Pasar Petisah.

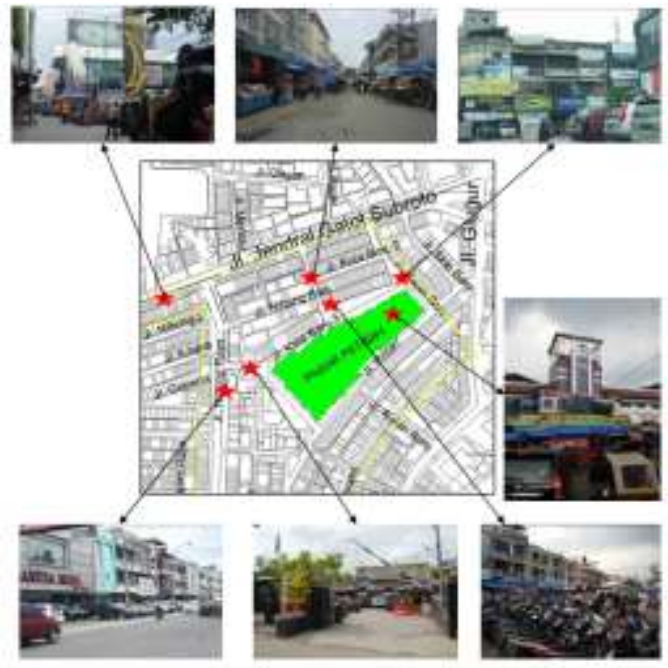

Gambar 1. Potensi Landmark Kawasan (Lindarto, 2016)

Potensi jalur (path) jalan Nibung Raya- Jalan Nibung Baru (Path A). jalur jalan Nibung Baru 3 - jalan Gatot Subroto (Path B), jalur sepanjang tepian antara ujung jalan Nibung Baru 3 dan jalan Gatot Subroto (Path C) merupakan infrastruktur menarik kawasan

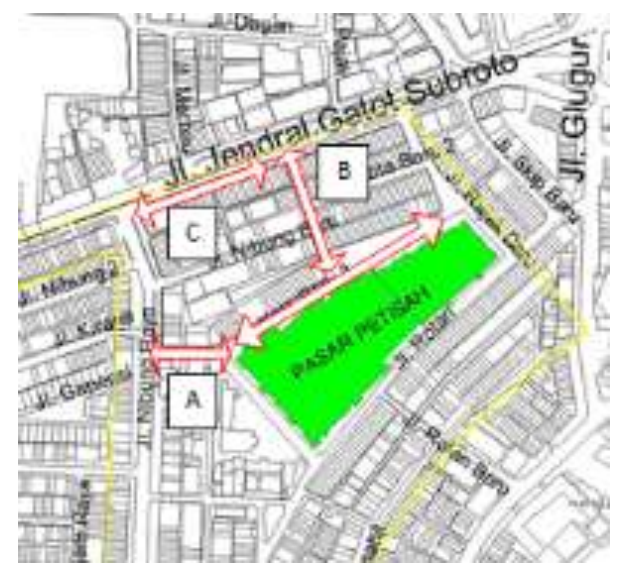

Gambar 2. Potensi Path Kawasan (Lindarto,2016)

Potensi daya tarik district kawasan berupa district pasar Petisah, district Carefour, district ruko kado, district Jalan Nibung dan district kantor Pemerintahan. 


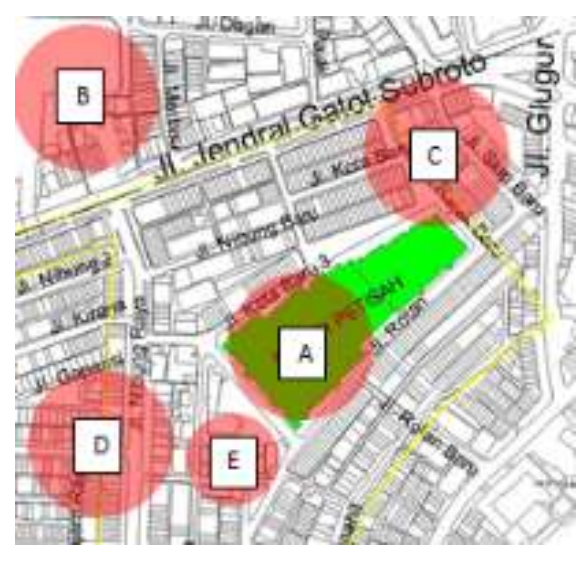

Gambar 3. Potensi District Kawasan (Lindarto,2016)

Potensi daya tarik edge dalam pengertian ruang perbatasan antara kegiatan berupa trotoar atau jalur pemisah antara kendaraan dan pejalan kaki meliputi hampir seluruh tepian ruang luar kawasan kajian.

Simpul jalan (node) sebagai simpangan jalan yang menarik bagi masyarakat untuk penentuan orientasi perjalanan dimaksud adalah simpang kantor polisi, simpang parkiran jalan Nibung 3 dan Simpang Gatot Subroto

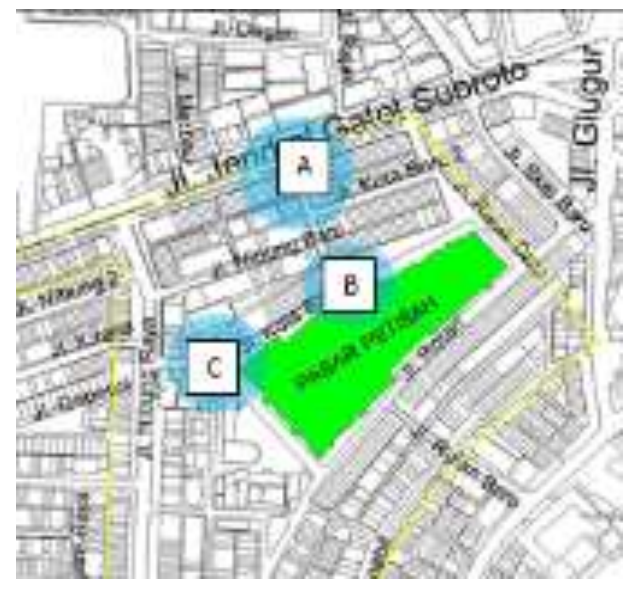

Gambar 4. Potensi Node Kawasan (Lindarto,2016)

Terdapat beberapa tempat dengan karakter kegiatan dagang yang khas misalnya kuliner khas Medan, India dan fashion kaki lima berada di tepian jalan Gatot Subroto, Parkiran Jalan Nibung Baru, Koridor jalan Nibung Baru.

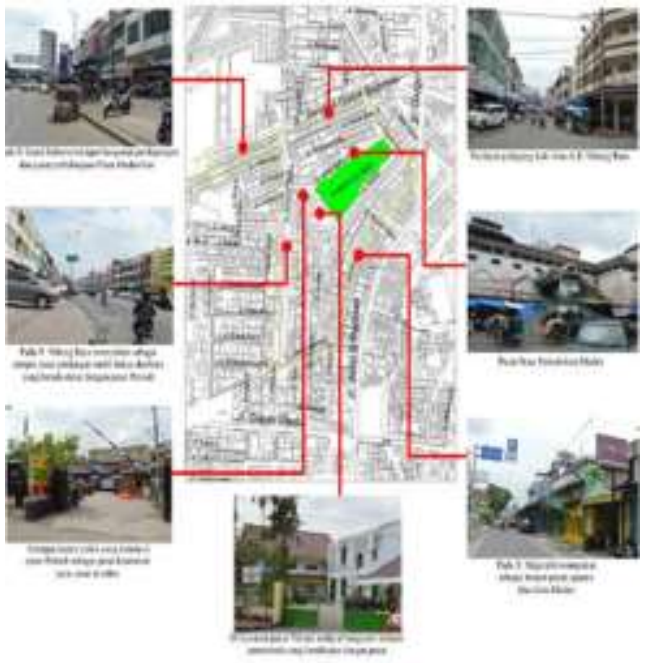

Gambar 5. Potensi kegiatan berkarakter khas (Lindarto, 2016)

Potensi Linkage Visual ditunjukkan pada gambar berikut :

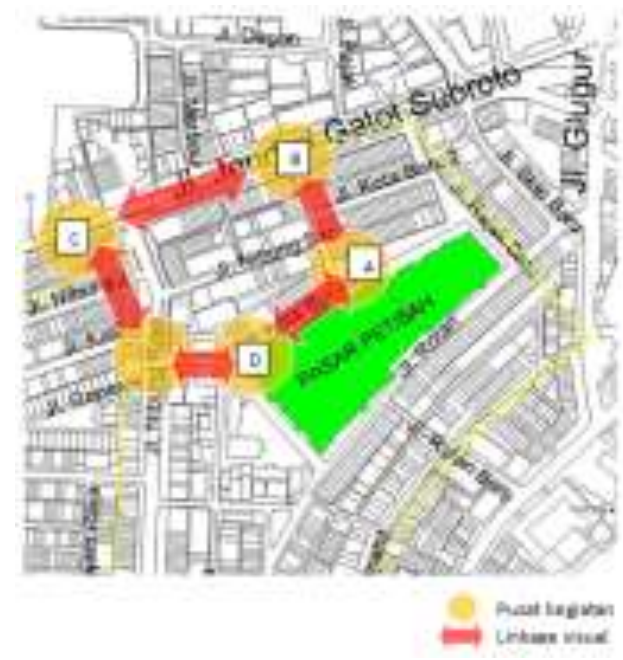

Gambar 6. Potensi Tempat dan Linkage Visual (Lindarto, 2016)

Pembentuk tempat dan linkage visual antara lain adalah bentuk lapak kegiatan pedagang kaki lima, ragam jual beli, potensi bangunan ruko yang ada, sarana pedestrian, dan infrastruktur kota. 


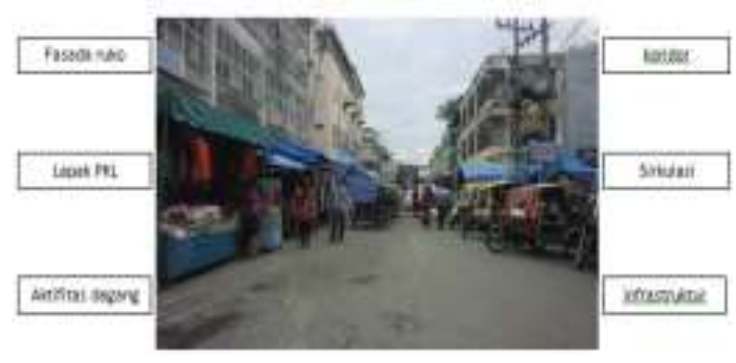

Gambar 7. Elemen karakter fisik kegiatan

Arahan Zonasi Kawasan Pasar Petisah

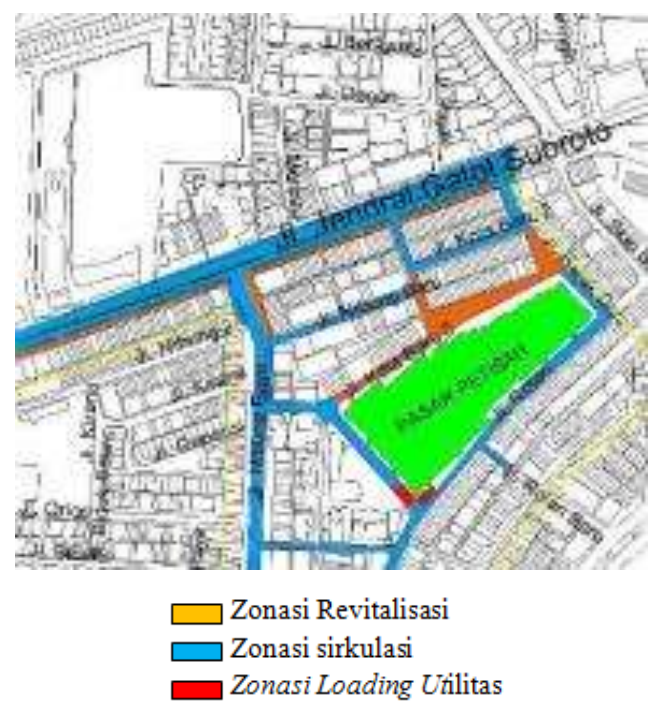

Gambar 8. Arahan zonasi Kawasan Niaga Pasar Petisah

\section{HASIL DAN PEMBAHASAN}

\section{Rancangan Model Desain Revitalisasi Pasar Petisah}

Karakter rancangan model desain revitalisasi kawasan Pasar Petisah Medan dilakukan dengan konsep mengangkat daya tarik sense of place, linkage visual dan karakter tempat. Pendekatan melalui penerapan elemen urban design [8] diwujudkan menjadi gambaran prarencana arsitektural rancangan desain model sebagai berikut :

\section{Model Sirkulasi Kawasan}

Tatanan sirkulasi kawasan dengan model sentralisasi parkir dan pengutamaan jalur pejalan kaki sebagai suatu tema street market mengacu konsep pedestrianisasi - walkability [9], yaitu ruang yang nyaman dan ramah bagi pejalan kaki.

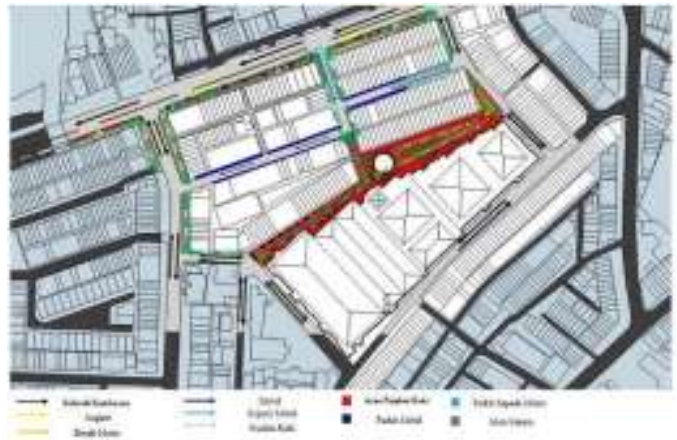

Gambar 9. Model Sirkulasi Pasar Petisah

Model Zonasi

Model zonasi wilayah membagi wilayah antara lain dengan penguatan path/jalur - node landmark secara tematik per segmen (street market - food court - public place)

Model Zonasi Street Market

Street market model kaki-lima dengan booth (kios) atraktif, terbuka dan mengalir. Sehingga konflik pergerakan lintasan kendaraan dan aktifitas pedagang dapat diminimalisir [10].

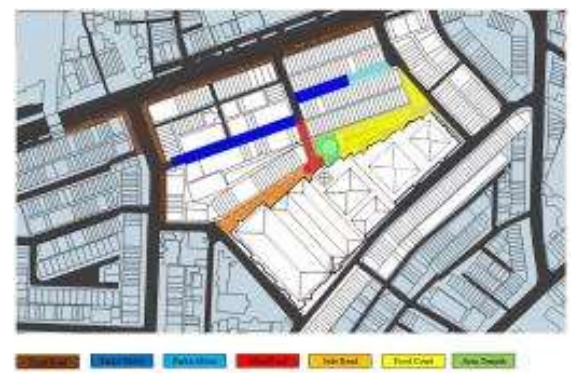

Gambar 10. Model Sirkulasi Pasar Petisah

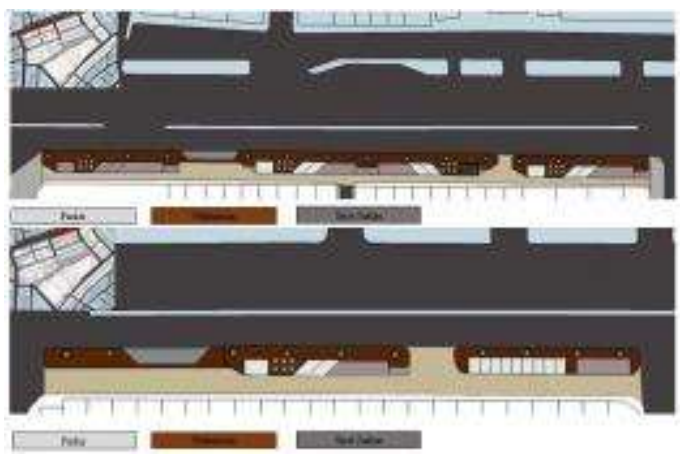

Gambar 11. Konsep Zonasi Street Market Pasar Petisah

Model Zonasi Food Court

Food court mengutamakan pedagang dengan tema masakan khas setempat. Dilengkapi dengan panggung atraksi terbuka. 

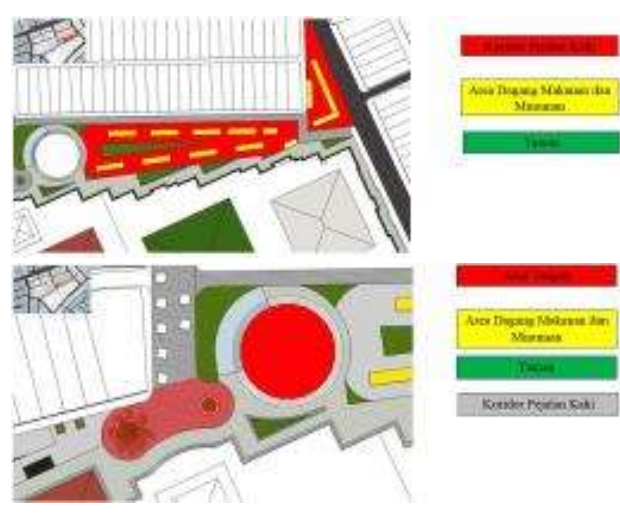

Gambar 12. Model Zonasi Food Court

Master Plan model rancangan desain revitalisasi pasar Petisah menyatukan (linkage) kegiatan niaga di wilayah sekitar dengan model peluberan kegiatan ramai, Linkage dimaksud menghubungkan Kawasan Petisah, Kawasan Carefour dan Kawasan Nibung sehingga semua aktifitas pengguna mendapat peluang dalam menggunakan ruang di kawasan dalam waktu yang sama.

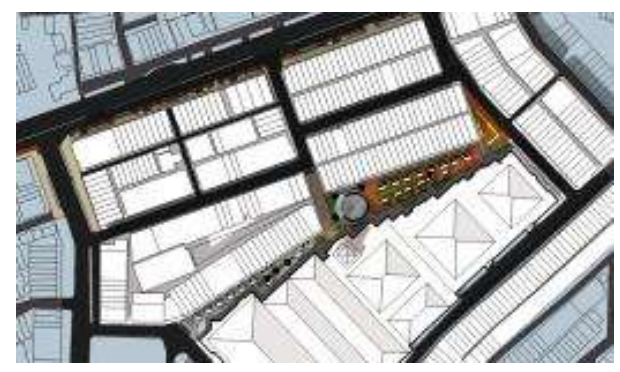

Gambar 13. Master Plan Model Revitalisasi Pasar Petisah

Model Food Court Booth

Food court booth, atau tempat berdagang makanan, berbahan kotak baja (container\}, berlantai dua dimaksudkan untuk memperluas kapasitas tempat berdagang dan sebagai solusi tempat berdagang sementara.

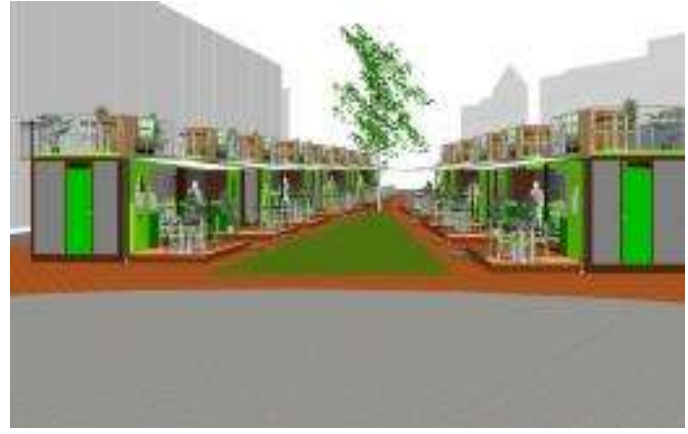

Gambar 14. Model Food Court Booth

Model Public Place

Public Place merupakan ruang publik tempat yang diperuntukkan bagi seniman setempat dan terbuka untuk pentas atraktif termasuk pedestrian yang dirancang sebagai livable space yaitu manambah ketersediaan ruang publik sebagai tempat interaksi yang hidup [11].

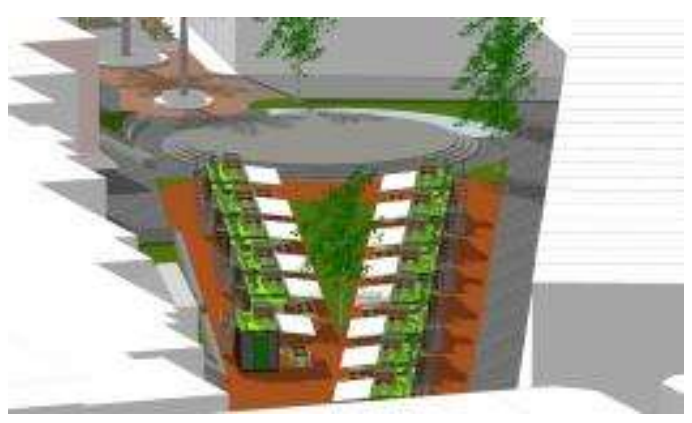

Gambar 15. Model Public Place

Model ruang parkir terbagi menjadi parkir terkelompok / cluster di area belakang ruko sehingga terjadi pemisahan sirkulasi kendaraan dengan jalur pedestrian dalam meningkatkan kenyaman pengguna kawasan.

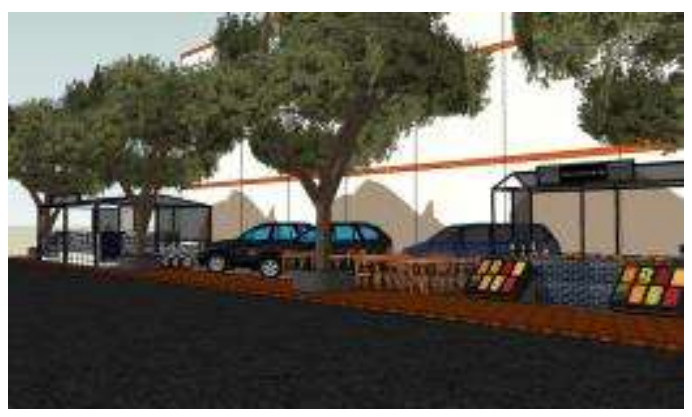

Gambar 15. Model Parkir Kawasan 
Model Booth Portabel,dirancang berupa container yang mudah diangkat pindahkan, dengan maksud yang sama dengan model food court booth. Penggunaan sistem kotak baja modular ini juga dilakukan mengingat efisiensi kebutuhan ruang pada kawasan, kemudahan konstruksi dan kebebasan aplikasi bentuk.

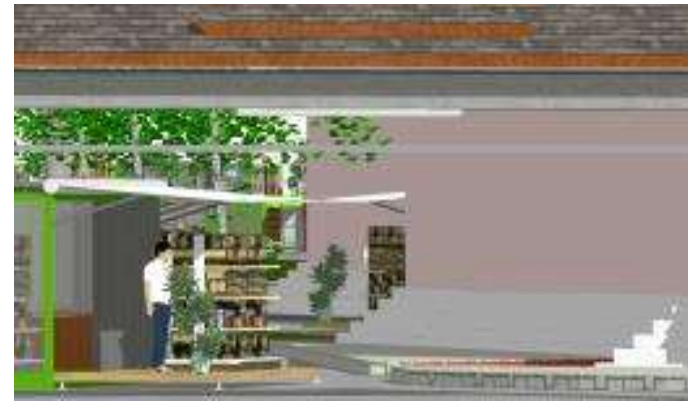

Gambar 16. Suasana Booth portabel

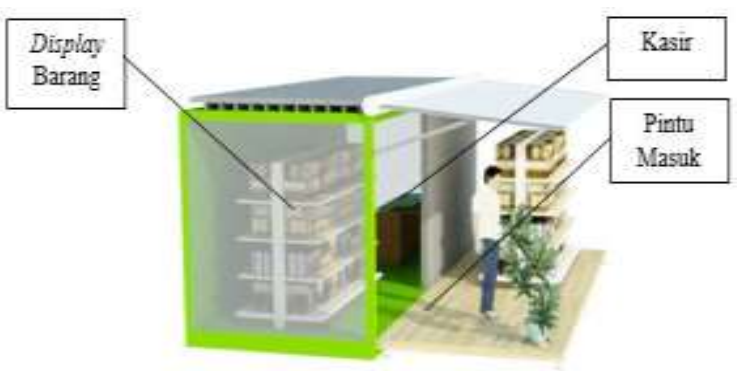

Gambar 17. Model Booth Portabel

Model Interior Booth

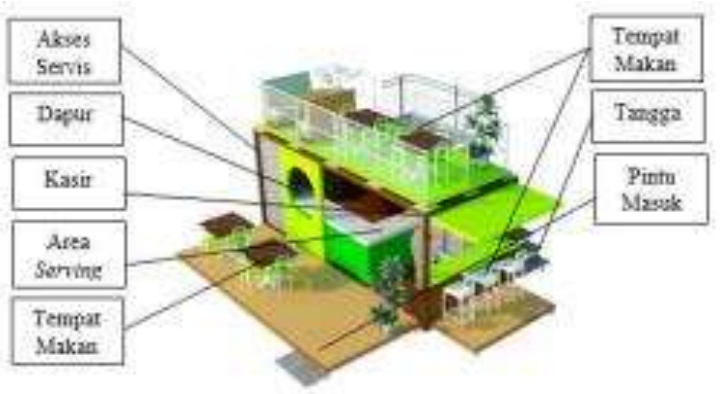

Gambar 17. Model Interior Booth

\section{Pedestrian}

Secara umum menyuguhkan kenyamanan dalam teduhan pepohonan, bahan yang tahan lama dan jalur sirkulasi yang mudah dan dekat antar booth.

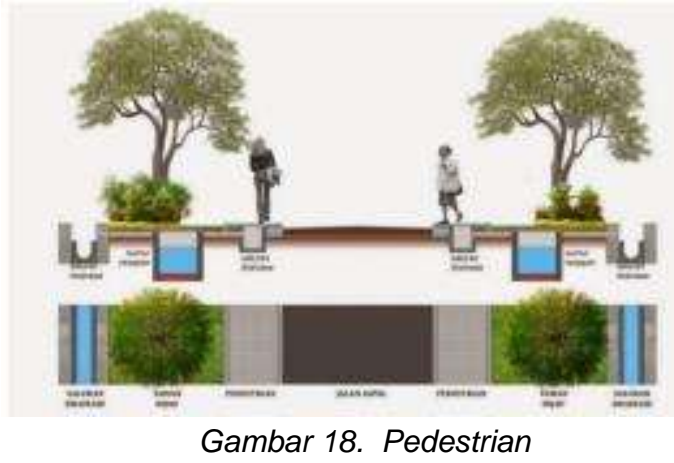

\section{KESIMPULAN}

Model rancangan Desain Revitalisasi Pasar Petisah ini merupakan perancangan komprehensif dengan panduan konsep Urban Retrofitting menggubah tatanan pasar sesuai potensi kearifan tempat, kearifan perilaku sosial ekonomi pengguna kawasan dan kearifan lingkungan setempat.

Dasar pemikiran model desain revitalisasi ini mengungkapkan kembali (re-inventing) potensi sense of place, linkage visual dan karakter tempat sehingga menjadikan model perancangan ini mampu tampil beridentitas.

Pasar Petisah memperoleh kembali roh kegiatannya (genius locus) melalui penghubungan kegiatan pasar Petisah dengan potensi kegiatan niaga sekitarnya seperti PKL dan Carefour (Mall Medan Fair) sehingga mampu memperpanjang life-time kegiatan niaga sebagaimana konsepsi hybrid traditional market [12], yaitu menggabungkan pasar sebagai ruang ekonomi, ruang sosial dan ruang terbuka sebagai tambahan untuk mengakomodasi kegiatan keramaian masyarakat.

Model perancangan ini diharapkan mampu menjadi alternatif panduan / guide lines bagi kegiatan revitalisasi kawasan niaga perkotaan yang lebih berkarakter. Perancangan Model Revitalisasi ini akan lebih bermakna jika dapat dilanjutkan dengan kajian detail engineering drawing, kajian sosial-ekonomi dan kebijakan publik yang berguna melengkapi konsep revitalisasi kawasan Pasar Petisah. 


\section{UCAPAN TERIMA KASIH}

Penulis mengucapkan terima kasih kepada Universitas Sumatera Utara dan Direktorat Jenderal Pendidikan Tinggi Kementerian Riset, Teknologi dan Pendidikan Tinggi $\mathrm{RI}$ atas pendanaan Penelitian Terapan TALENTA USU 2017 dengan judul Model Perancangan Revitalisasi Kawasan Niaga Mendukung Pengembangan Wilayah Kota.

\section{DAFTAR PUSTAKA}

[1] Lindarto, Dwi. (2015). Kajian Faktor Place Attachment sebagai pembentuk Cluster Kawasan Niaga. Proseding Seminar Ilmiah Nasional, USU Press. Medan.

[2] Lynch, Kevin. (1981). The Theory of Good City Form. The M.I.T. Press. Cambridge, Massachusetts.

[3] Dunham-Jones A, Williamson J. (2009). Retrofitting Suburbia: Urban Design Solutions for Redesigning Suburbs. Hoboken, NJ: John Wiley \& Sons.

[4] Schultz, Christian-Norberg. (1991). Genius Loci, towards a phenomenology of architecture. Rizzoli, New York.

[5] Lindarto, Dwi. (2016). Jelajah Tempat Berkarakter bagi Model revitalisasi Pasar Petisah Medan, Prosiding Seminar Nasional IPLBI 2016. IPLBI Press, Bandung.

[6] Creswell, John W. (2009). Research Design: Qualitative, Quantitative, and Mixed Methods Approaches. London: Sage Publications, Inc.

[7] Lynch, Kevin. (1960). The Image of The city. The M.I.T. Press. Cambridge, Massachusetts.

[8] Barnett, Jonathan. (1982). Introduction to Urban Design. Harper \& Row publisher, New York.

[9] Choi, Eunyoung. (2012). Walkability as an Urban Design Problem :Understanding the activity of walking in the urban environment. Licentiate Thesis 2012 KTH Royal Institute of Technology Architecture and the Built Environment School of Architecture SE10044 Stockholm Sweden

[10] Burden, Dan. (2000). Streets and Sidewalks, People and Cars: The
Citizens Guide to Traffic Calming. Local Government Commission Center for Livable Communities,

[11] Shuhana Shamsuddin, et al. (2013). Walkable in order to be livable, the Centre for Environment-Behaviour Studies (cEBs), Faculty of Architecture, Planning \& Surveying, Universiti Teknologi MARA, Malaysia

[12] Wibowo, Arif dkk. (2014). Hybrid Traditional Market : Menuju Pengembangan Pasar Tradisional yang Ramah Sosial dan Ekologi Kota dalam Upaya Memperkuat Ekonomi Kerakyatan. Jurnal IImiah Green Technology 3. Jurusan Arsitektur, Fakultas Sains Dan Teknologi UIN Maulana Malik Ibrahim Malang. Malang. 
